\title{
Informação legislativa, acesso e cidadania
}

\author{
Sônia Domingues Santos Brambilla \\ Doutora; Assembleia Legislativa do Estado do Rio Grande do Sul, Porto Alegre, RS, Brasil; \\ sonia.brambilla@al.rs.gov.br
}

\begin{abstract}
Resumo: Este estudo destaca as principais ações desenvolvidas pela Assembleia Legislativa do Rio Grande do Sul para o provimento, por meio do seu portal na Internet, do direito à informação e ao acesso público. São objetivos específicos analisar o portal da ALRS e mapear as interfaces gráficas para verificar a visibilidade da informação e possibilidades de interatividade. O estudo identifica uma visibilidade média e um alto nível de interatividade na maioria das interfaces gráficas. Conclui, dessa maneira, que o portal da Assembleia Legislativa constitui um ambiente público de acessibilidade que provê visibilidade e oferece múltiplos serviços, atuando, portanto, como facilitador do acesso à informação.
\end{abstract}

Palavras-chave: Acesso à informação. Direito à informação. Visibilidade. Interatividade. Informação legislativa.

\section{Introdução}

A Constituição garante aos brasileiros o acesso à informação produzida pelo Estado e obriga os agentes públicos a obedecerem ao princípio da publicidade. Esse processo dá origem a um fenômeno de auto alimentação, visto que quanto mais informação é disponibilizada para a sociedade, mais cresce a demanda por transparência, mais competentes são as contribuições vindas de fora do Estado e, por fim, maior é o número e a qualidade da informação que o governante tem à sua disposição.

O acesso à informação, no entanto, não ocorre em condições iguais para todos os segmentos da sociedade, seja pela ineficiência e descaso de alguns órgãos e autoridades, seja pela diferença nas condições de vida dos diversos grupos sociais. O desenvolvimento tecnológico que se verificou no país nos últimos anos possibilitou a aquisição de computadores e o acesso à Internet, porém não igualmente para todos. Sabe-se que grande parte do povo brasileiro ainda é vítima da injustiça social e não tem satisfeitas todas as suas necessidades básicas de 
sobrevivência, estando também excluída, muitas vezes, do universo da informação eletrônica.

De acordo com Lèvy (1993), a Internet é uma organização elitista, visto que parte da população mundial sequer usa o telefone. Nesse contexto, portanto, a exclusão digital se apresenta como uma faceta da exclusão social. Assim sendo, colocar as informações à disposição da sociedade, de forma igualitária, constitui uma tarefa das instituições públicas, especialmente daquelas empenhadas na promoção da cidadania e na defesa dos valores e da dignidade humana.

Partindo da percepção de que a democratização da sociedades se constrói também com a democratização das informações, do conhecimento, da formulação e debate de ideias, este trabalho pretende-se destacar quais as principais ações desenvolvidas pela Assembleia Legislativa do Rio Grande do Sul, doravante denominada ALRS, em prol do provimento do direito à informação e ao acesso público, por meio do seu portal na Internet (<http://www.al.rs.gov.br $>)$. São objetivos específicos analisar o portal da ALRS para mapear os serviços disponibilizados ao público e, em seguida, verificar as possibilidades de interação, de interatividade e de visibilidade da informação.

É importante ressaltar as características plurais e democráticas do Poder Legislativo; a publicidade e o acesso imediato às discussões e aos processos legislativos fazem dele um poder mediador, representante dos múltiplos interesses da sociedade e, desta forma, porta-voz dos cidadãos. $\mathrm{O}$ incremento crescente da consciência política e do debate público tem uma importância vital para a independência do Poder e para o bem-estar democrático. Nesses moldes, o portal da ALRS deve se constituir num espaço público, acessível e aberto à participação da comunidade.

No decorrer do trabalho, serão abordados, no referencial teórico, o acesso público e o direito à informação, além da contextualização da Assembleia Legislativa do Estado, sua estrutura organizacional e as etapas do processo legislativo. 


\section{Contexto Institucional}

A história do Parlamento gaúcho se inicia em 20 de abril de 1835, quando foi instalada, no Casarão Rosado da antiga Rua da Igreja (atualmente denominada Rua Duque de Caxias) em Porto Alegre/RS, a Assembleia Provincial do Império. Esse foi também o ano de deflagração da Revolução Farroupilha no Estado, no dia 20 de setembro. Na sessão de instalação, o Presidente da Província, Antônio Rodrigues Fernandes Braga, acusou o Deputado Bento Gonçalves de articular a separação do Rio Grande do Sul, então Província de São Pedro do Rio Grande do Sul do Império (PESAVENTO, 1996).

A Assembleia Legislativa funcionou neste local até setembro de 1967, quando se transferiu para a atual sede, o Palácio Farroupilha, na Praça Marechal Deodoro - também conhecida como Praça da Matriz. Ao longo da história, o Parlamento gaúcho tem sido celeiro de líderes cuja projeção ultrapassam as fronteiras do Estado.

$\mathrm{Na}$ atual legislatura, estão representados na Assembleia gaúcha 10 partidos políticos, sendo 55 deputados eleitos pelo povo em voto direto, com a missão de cumprir, dentre outras, as principais funções do Poder Legislativo: legislar, fiscalizar e controlar os atos do Governo Estadual. Para tal, os parlamentares gaúchos apresentam e votam projetos de lei nas sessões plenárias, atuam em Comissões e realizam audiências públicas, onde temas prioritários para o Estado são discutidos. A Mesa é o órgão que, por meio do seu Presidente, além de coordenar os trabalhos legislativos, representa e administra a Assembleia Legislativa. É eleita pelos próprios deputados e formada com participação pluripartidária.

A função legislativa consiste em apresentar, discutir e deliberar os projetos de leis, resoluções, emendas e outras proposições legais. Essas propostas, se aprovadas, podem se tornar uma nova lei ou alterar uma existente. A lei surge das demandas da sociedade, garantindo direitos e instituindo deveres.

Antes de serem votadas, as proposições passam por um amplo debate nos órgãos técnicos, onde, por meio de audiências públicas, ouvem tanto represen- 


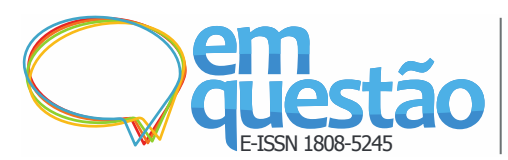

tantes de classe quanto a sociedade em geral, elaboram estudos e emitem pareceres. As Comissões estão estruturadas como segue:

a) permanentes, para examinar a constitucionalidade e a pertinência das propostas: Comissão de Agricultura, Pecuária e Cooperativismo; Comissão de Assuntos Municipais; Comissão de Cidadania e Direitos Humanos; Comissão de Constituição e Justiça; Comissão de Economia, Desenvolvimento Sustentável e do Turismo; Comissão de Educação, Cultura, Desporto, Ciência e Tecnologia; Comissão de Finanças, Planejamento, Fiscalização e Controle; Comissão de Saúde e Meio Ambiente; Comissão de Segurança e Serviços Públicos; Comissão Mista Permanente de Defesa do Consumidor e Participação Legislativa Popular; e Comissão Mista Permanente do Mercosul e Assuntos Internacionais;

b) temporárias, podendo ser Especiais, de Inquérito ou de Representação Externa, todas destinadas a averiguar fatos específicos e eventuais.

O processo legislativo consiste em um encadeamento de atos - iniciativa, emenda, votação, sanção/veto, promulgação e publicação previamente sistematizados e visando à elaboração de emendas à Constituição, leis complementares e ordinárias, decretos legislativos e resoluções. É regulado pela Constituição Federal - na medida em que fixa regras de competência para os Estados -, pela Constituição Estadual e pelo Regimento Interno da Assembleia Legislativa. A iniciativa das proposições pode ser dos Deputados, de uma Comissão, da Mesa, de outros poderes, do Ministério Público ou de ordem popular, por meio de órgãos representativos (RIO GRANDE DO SUL, 2015).

Em média, mais de 2000 pessoas circulam diariamente pelo Palácio Farroupilha, para participar de audiências públicas e eventos, acompanhar sessões plenárias, usar computadores públicos do espaço AL.COM no saguão de entrada do prédio, utilizar a Biblioteca, o Memorial e a Escola do Legislativo, ou para visitar as instalações do Parlamento Gaúcho. Além disso, a Assembleia tem buscado ampliar o acesso às informações disponíveis em seus sistemas através de sua página na Internet e pelo portal Transparência com o objetivo de dar visibilidade e publicidade às informações institucionais. 


\section{Acesso à informação pública}

No contexto das atividades-fim de uma casa legislativa, considera-se como informação todo e qualquer dado, mensagem ou ideia, registrada ou verbalizada, que, de alguma forma, permita aos agentes envolvidos no processo conhecer, acompanhar, interferir e decidir a respeito das diferentes questões de interesse da sociedade (MARQUES JR.; PIMENTA; FARIA, 2000).

É por meio da informação, portanto, que se busca, além de apoiar internamente a atividade legislativa enquanto papel institucional, atingir a sociedade como um todo, através do incentivo à participação em eventos e debates, da oferta de cursos e programas de capacitação, da veiculação e divulgação de informações, da prestação de serviços e da preservação da memória política estadual.

Pode-se entender a informação pública como "[. . . ] não apenas o acesso ao conhecimento, mas também a participação ativa dos cidadãos na tomada de decisão e na formulação de políticas públicas.” (LOPES, 2006, p. 5). No Manual da Organização para a Cooperação e Desenvolvimento Econômico (OCDE), está dito que os cidadãos devem ser considerados parceiros por assumirem um papel nesse processo, numa relação bidirecional com o poder público (BRASIL, 2002). Em tese, qualquer pessoa pode ter acesso às informações públicas, que vão desde políticas até ao funcionamento da estrutura estatal e dos serviços prestados pelas instituições. Entretanto, o que deve determinar se a informação pode ser pública é a sua utilidade para o cidadão, e não as decisões do próprio órgão regulador (LOPES, 2006). Isto dificulta o cometimento de abusos, como por exemplo a disseminação de práticas que beneficiam poucos e que tornam a população, muitas vezes, impotente para exercer seu papel democrático de fiscalizadora das atividades políticas e governamentais.

Desde a Constituição de 1988, a regra é que toda informação, sendo de interesse público ou mesmo de mero interesse particular do requerente, deve ser disponibilizada. Assim, em termos constitucionais, tem-se hoje que: 


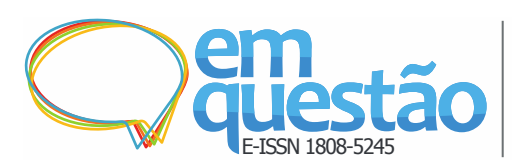

Art. 15, Inciso XXXIII - todos tem o direito a receber dos órgãos públicos informações de seu interesse particular, ou de interesse coletivo ou geral, que serão prestadas no prazo da lei, sob pena ou responsabilidade, ressalvadas aquelas cujo sigilo seja imprescindível à segurança da sociedade e do Estado. (BRASIL, 2015).

Para afirmar esse direito, a Lei Federal 12.527, de 18 de novembro de 2011, estabelece que o acesso a informações públicas é direito fundamental de todo cidadão (BRASIL, 2011). Portanto, o sigilo da informação só pode existir se, por algum motivo, trouxer proteção ou benefício ao cidadão, devendo os atos oficiais obedecer aos princípios da publicidade e da transparência.

As Tecnologias da Informação e da Comunicação (TICs) vieram para auxiliar a gestão pública e também para redefinir as relações entre governos, cidadãos e grupos sociais, reduzindo principalmente o tempo e os custos, e gerando, assim, uma nova forma de democracia, a digital. Esta seria concretizada no ambiente virtual da Internet, o Ciberespaço, aonde seus representantes viveriam conectados e participando de redes de mobilização ou protesto (TAPIA, 2005). Nessa visão otimista, o autor afirma que o cidadão, bem informado, sintonizado com sua época e disposto a agir coletivamente, superaria os obstáculos identificados pela teoria democrática, como o individualismo e a descrença na capacidade de mobilização, nos partidos políticos e nos próprios políticos.

Uma outra visão, entretanto, apesar de reconhecer essas vantagens, questiona o reducionismo dos conceitos em torno da democracia digital, que converteria os indivíduos em espectadores passivos. A utilização das TICS para o acesso à informação pública só faria sentido se o fim fosse associado à formação da cidadania. Caso não atenda a esse aspecto, os usuários poderiam se tornar meros "usuários" - mais satisfeitos e menos preocupados em participar (TAPIA, 2005). Além disso, é preciso saber se a comunidade é eletrônica. Em um país como o Brasil, de fortes desigualdades sociais, ainda é importante refletir sobre os riscos da exclusão digital, que acaba acarretando a exclusão social dos que não tem acesso ou não dominam a técnica da informática.

Certamente, a democracia digital e suas estratégias de formação da cidadania são uma realidade, e cabe apenas desenvolver estratégias que combinem 
as inovações tecnológicas de gestão da informação com os mecanismos tradicionais de participação social. Os órgãos públicos devem pois, apresentar projetos de inclusão digital para, a partir daí, assumirem uma postura dinâmica, oferecendo produtos e serviços no ambiente virtual que contemplem mecanismos de interatividade que envolvam todos os atores desse processo.

\section{Direito à informação}

A informação é um dos pressupostos básicos para o exercício da cidadania. É por meio dela que o cidadão tem condições de conhecer e cumprir seus deveres, bem como de entender e reivindicar seus direitos. É ainda com base neste fato que a sociedade civil pode acompanhar, contribuir e ocupar seu espaço perante a estrutura e os poderes do Estado.

Por consequência, para ter acesso ao poder público, o cidadão precisa ter assegurado o direito à informação, que é compreendido como "[...] um direito que assegura outros direitos, confere condições de igualização de sujeitos e oferece visibilidade ao poder e ao mundo." (GENTILLI, 2005, p. 128). Todos os direitos se relacionam a ele de alguma forma, sendo premissa básica para o alargamento da cidadania e para formar indivíduos emancipados, isto é, capazes de avaliar as questões de forma autônoma.

É nesse contexto que se deve pensar o direito à informação que, segundo Gentilli (2005), pode ser visto a partir de duas vertentes: na perspectiva de um direito para todos; e na perspectiva de fornecer informações em quantidade e qualidade para o melhor julgamento possível de cada um. Pode ter características emancipatórias ou de tutela, e deve ser concebido por prerrogativas garantidas por lei ou por provimento (direitos sociais garantidos pelo Estado), pois o cidadão não pode escolher entre receber ou não uma informação. Deve, sim, ser fornecido a ele o necessário para que cumpra com suas obrigações legais.

No campo dos direitos políticos, a informação é imprescindível, sobretudo, para o exercício do voto consciente (GENTILLI, 2005). Além disso, também é importante para o acompanhamento das atividades do governo, dos movimen- 
tos e discussões do parlamento, e para garantir a publicidade dos atos governamentais.

Cabe distinguir apenas a esfera pública da informação daquilo que é privativo a cada indivíduo. Citando novamente Gentilli (2005), resume-se a questão da seguinte forma: dar o máximo de publicidade ao que se refere à esfera pública e manter secreto o que é privado. Porém, a distinção entre esses meios fica cada vez mais difícil, tornando complicada a proteção desse direito.

Nos tempos atuais, o espaço público é poroso, isto é, permeável e não totalmente sólido, e não pode ter sua agenda predefinida por critérios de moral e política. Vieira (2001) define essa esfera como um lugar de discussão e debate, atuando como instância mediadora entre os impulsos comunicativos gerados na sociedade civil e as instâncias que articulam institucionalmente as decisões políticas do Parlamento. Nessa visão, os grupos de excluídos seriam compensados mediante políticas diferenciadas debatidas de modo público, atendendo ao conceito de cidadania participativa - da igualdade do direito a se ter direitos e a participar ativamente em defesa deles - em que os cidadãos exercem a função de críticos do Estado.

\section{Procedimentos Metodológicos, Análise e Interpretação dos Resultados}

Para destacar as principais ações desenvolvidas pela Assembleia Legislativa do Rio Grande do Sul (ALRS) no provimento do direito à informação e ao acesso público, mapearam-se os serviços disponibilizados no seu portal da Internet. Após, verificou-se a visibilidade da informação, aqui considerada, segundo Serpa (2007), como a representação física no espaço público, e apresentaramse as possibilidades de interatividade providas pelo Poder Legislativo nos principais serviços oferecidos nesse ambiente virtual.

Neste estudo foram utilizados as definições de Filatro (2008) para interação e interatividade; segundo a autora, a interação precisa ser intencionalmente planejada e expressa, visual e funcionalmente, na interface, estando ligada à ação recíproca pela qual os indivíduos e objetos se influenciam mutuamente. Já a interatividade descreve a capacidade potencial do sistema de proporcionar 
interação. Assim, a interface pode ser conceituada como a área onde se dá a interação entre o usuário e o programa.

Neste âmbito, utilizando os níveis de Sims (1997), já empregados em trabalhos anteriores (ACQUOLINI, 2013; SILVA, 2015), pode-se mensurar o grau de interatividade de uma interface gráfica pelo número dos seguintes fatores, presentes simultaneamente no ambiente:

objeto: ao clicar, ocorre alguma forma de resposta audiovisual;

a) linear: permite ao usuário acessar a próxima tela (ou anterior) de acordo com sua sequência;

b) de suporte: permite acessar mensagens de ajuda ou sistemas tutoriais;

c) de atualização: refere-se aos componentes de aplicação individual, ou eventos em que ocorre um diálogo entre o usuário e o conteúdo. A atualização pode variar desde uma simples pergunta e resposta até complexas respostas de inteligência artificial;

d) construtiva: permite manipular objetos para alcançar objetivos;

e) reflexiva: registra as respostas inseridas pelos usuários e permite que respostas anteriores sejam visualizadas, possibilitando que o usuário compare e reflita sobre elas.

f) de simulação: permite controlar ou operar, por escolha individual, a sequência do conteúdo;

g) hiperlinkada: permite ao usuário acessar informações e navegar livremente;

h) contextual não-imersiva: o usuário é transportado a um ambiente de treinamento virtual completo, onde pode realizar tarefas que refletem experiências de trabalho;

i) virtual imersiva: o usuário é inserido virtualmente em um ambiente no qual o computador responde a ações e movimentos individuais.

Na Figura 1, a seguir, visualiza-se o portal da ALRS. A partir dela, serão analisados os menus principais de acesso a fim de verificar, primeiramente, a visibilidade das suas interfaces gráficas: 
Figura 1 - Página Principal do Portal da ALRS na Internet

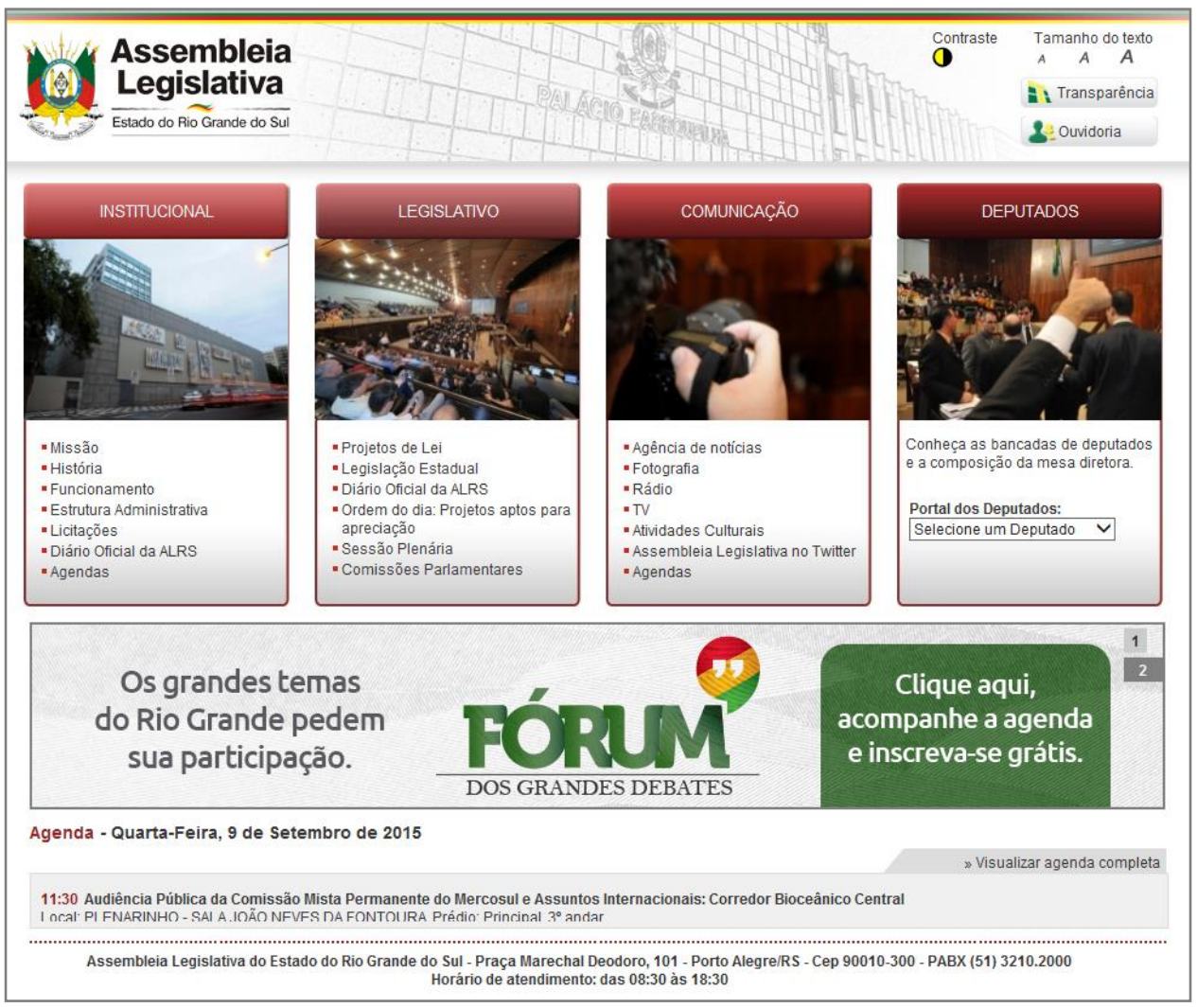

Fonte: Portal da Assembleia Legislativa do RS (RIO..., 2015)

Percebe-se, no portal da ALRS, que as informações estão categorizadas em quatro módulos, ou abas: na primeira aba - Institucional -, estão disponíveis as informações sobre a estrutura organizacional e administrativa da Assembléia; na aba Legislativo estão as informações referentes ao processo legislativo e às bases de dados de legislação; a seguir, no módulo Comunicação, estão dispostos os canais de mídia e de promoção artística e cultural; e por último, na aba Deputados, estão a composição das bancadas partidárias e o acesso às páginas dos deputados que integram a legislatura atual.

No topo e à direita da página, é possível acessar o portal da Transparência e a Ouvidoria; ambos órgãos voltados ao atendimento de demandas do cidadão sobre informações públicas. Na parte inferior da página, estão em destaque os principais eventos da ALRS e a agenda institucional, com a programação diária de todos os espaços, como as salas onde se reúnem as Comissões, o Plenarinho, o Espaço da Convergência e o Teatro Dante Barone. 
Uma análise geral da página principal do "ALRS” evidenciou seu caráter político. Enquanto há serviços para atendimento de interesses coletivos, há também a necessidade de representar a pluralidade de bancadas partidárias que compõem a legislatura, dando espaço aos parlamentares para divulgarem seus trabalhos. Pode-se afirmar, neste sentido, que o portal da ALRS tem se estabelecido como espaço público de aproximação com o cidadão, dando transparência e acesso às informações produzidas pelos deputados e servidores.

Para detalhar a visibilidade em todos os seus níveis, foram mapeadas, na aba Institucional, as seguintes interfaces, que compõem sub-portais com conteúdo próprio e acessíveis pela página principal da ALRS: Portais Transparência, Ouvidoria, Escola do Legislativo, Biblioteca Virtual e Memorial do Legislativo. As demais abas terão apenas suas interfaces principais analisadas totalmente, a fim de identificar canais de interação com os usuários. 


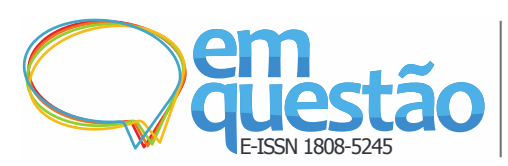

Informação legislativa, acesso e cidadania

Sônia Domingues Santos Brambilla

Figura 2 - Interface Gráfica da Aba Institucional do Portal da ALRS

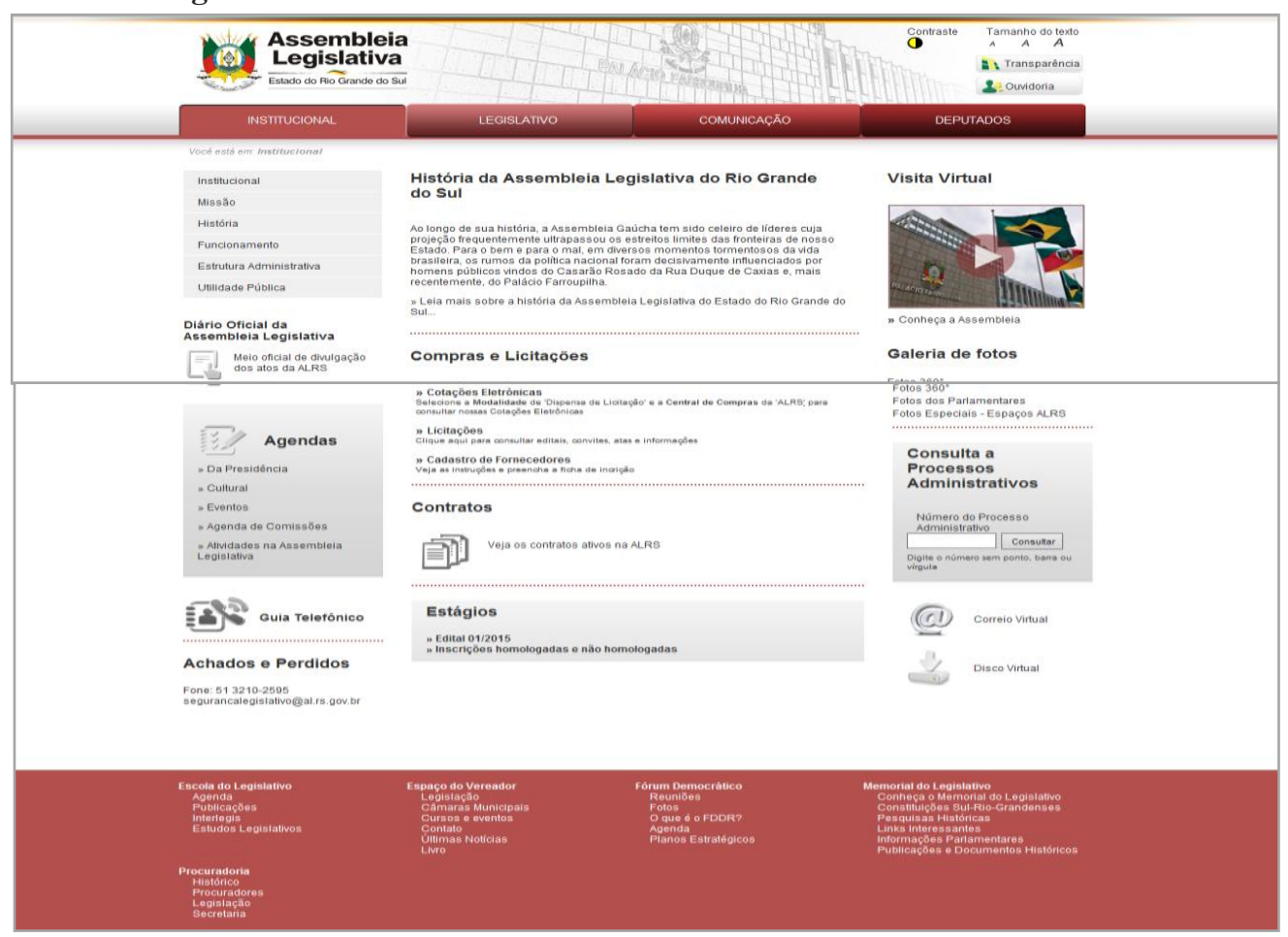

Fonte: Portal da Assembleia Legislativa do RS (RIO..., 2015)

\subsection{Portais Transparência e Ouvidoria}

Os portais Transparência e Ouvidoria estão visíveis já no primeiro nível da página principal da ALRS, e novamente em destaque na aba Institucional. Uma das finalidades do portal Transparência é a de contribuir para o aperfeiçoamento dos mecanismos de controle da gestão pública e, ainda, dar publicidade aos atos do Poder Legislativo, como mostra a Figura 3: 


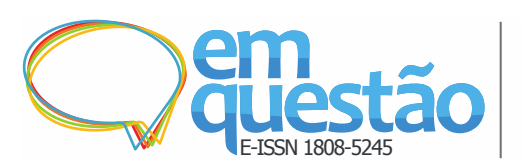

Informação legislativa, acesso e cidadania

Sônia Domingues Santos Brambilla

Figura 3 - Interface Gráfica do Portal da Transparência da ALRS

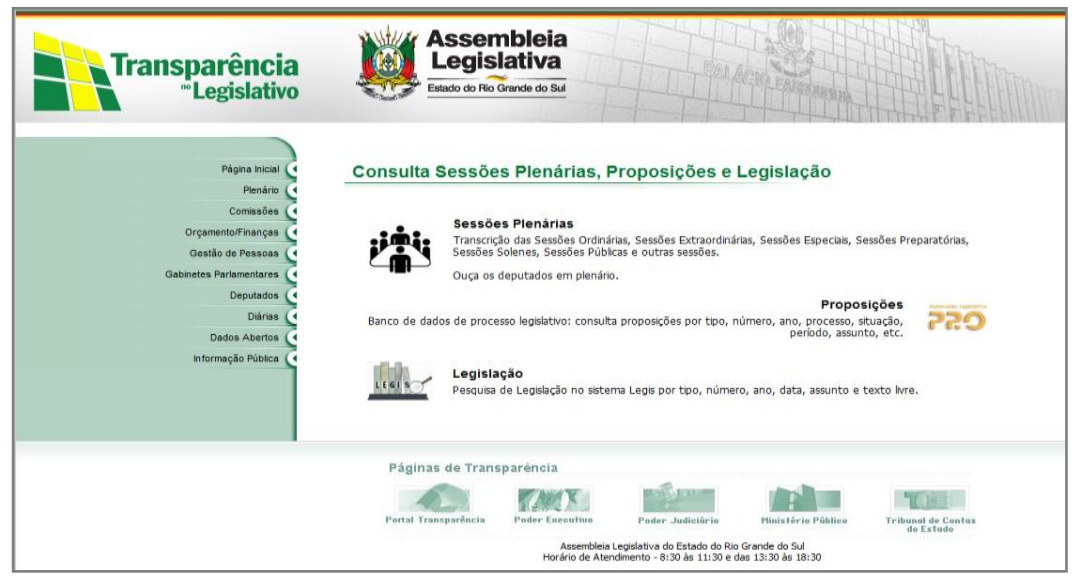

Fonte: Portal da Assembleia Legislativa do RS (RIO..., 2015)

Já o portal Ouvidoria estabelece um meio de comunicação entre o cidadão e o Poder Legislativo no qual a comunidade pode encaminhar reclamações, denúncias, sugestões e avaliações sobre o Parlamento, com a garantia, segundo consta, de que nenhuma demanda ficará sem resposta. Segue a interface de acesso:

Figura 4 - Interface Gráfica da Ouvidoria da ALRS

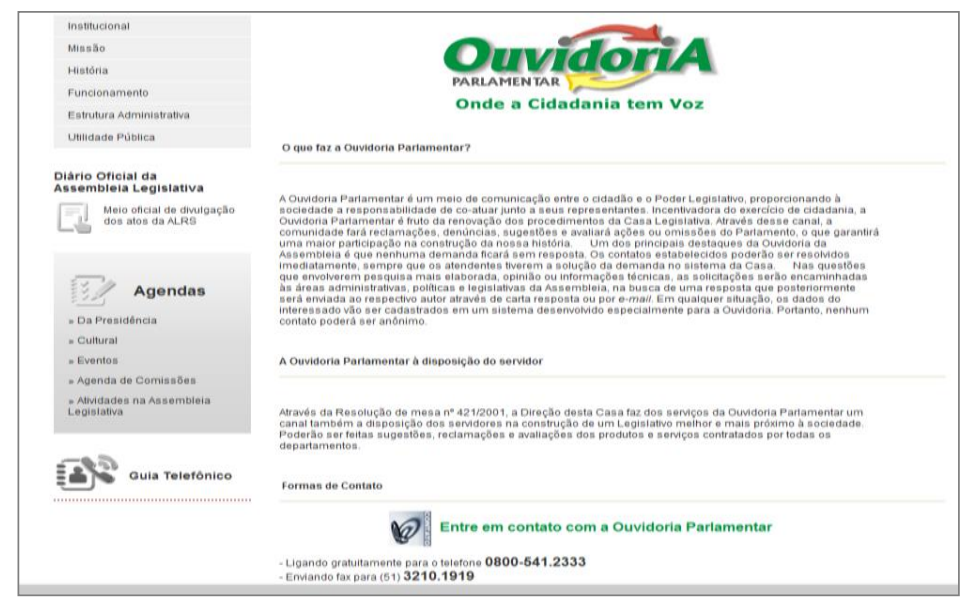

Fonte: Portal da Assembleia Legislativa do RS (RIO..., 2015)

Pode-se avaliar que as duas interfaces têm fácil acesso e navegação, com diversas alternativas de interação e informações relevantes sobre as ações e a execução orçamentária da instituição. 


\subsection{Escola do legislativo, biblioteca virtual e memorial do legislativo}

Segundo informa o portal da ALRS, a Escola do Legislativo tem como filosofia promover a educação para o exercício da cidadania, o fortalecimento do Poder Legislativo e sua aproximação com a sociedade. Sua interface principal está reproduzida na Figura 5: 


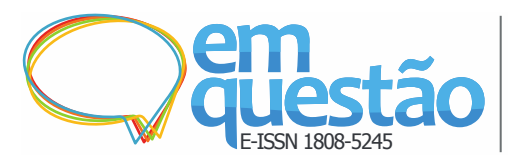

Figura 5 - Interface Gráfica da Escola do Legislativo

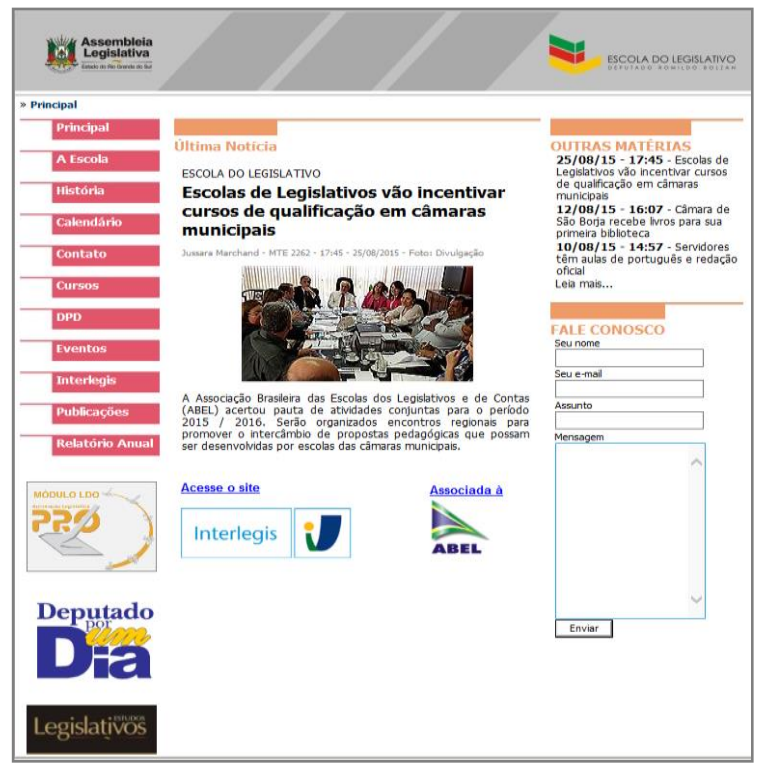

Fonte: Portal da Assembleia Legislativa do RS (RIO..., 2015)

São oferecidos pela Escola diversos projetos voltados à formação da cidadania, como o "Deputado por um Dia", onde cinco instituições de ensino, representadas por 11 alunos cada, elaboram um projeto de lei que será discutido e votado na "Sessão Plenária do Estudante". Também, além de serem ofertados cursos de qualificação aos servidores, é editada, anualmente, a "Revista do Legislativo", publicação destinada a refletir sobre temas de relevância para a área legislativa. A Biblioteca Virtual, inaugurada durante a Feira do Livro de Porto Alegre em 2007, oferece um ambiente na Internet com acesso ao catálogo online do acervo, o texto integral das obras produzidas pelo Parlamento, o blog da Biblioteca e o Fale Conosco, entre outras páginas. A interface gráfica é a seguinte: 


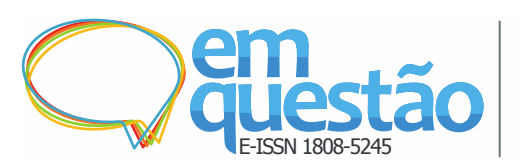

Informação legislativa, acesso e cidadania

Sônia Domingues Santos Brambilla

Figura 6 - Interface Gráfica da Biblioteca Virtual da ALRS

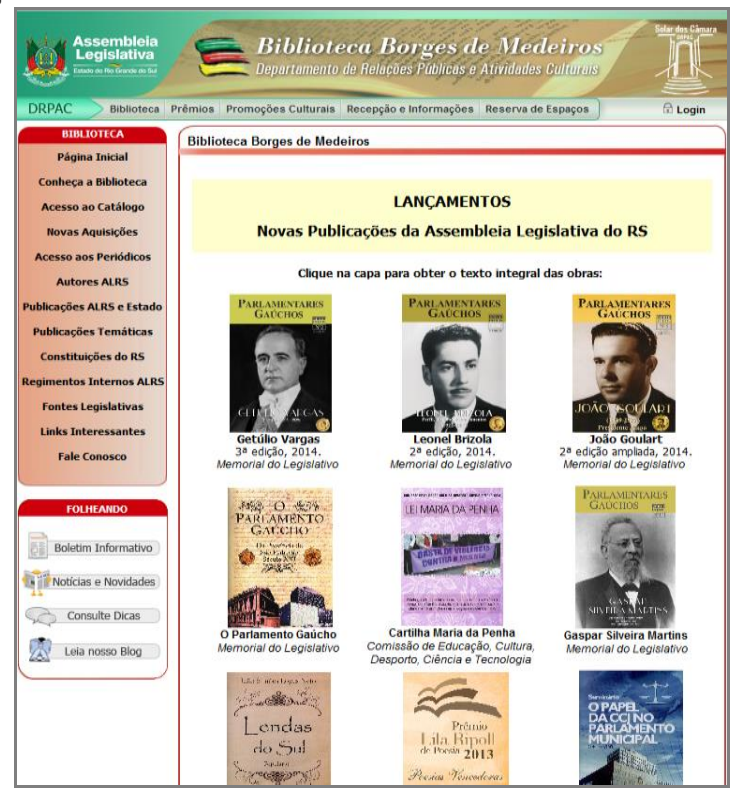

Fonte: Portal da Assembleia Legislativa do RS (RIO..., 2015)

Por sua vez, o Memorial do Legislativo tem como missão garantir a preservação, a conservação e acesso à memória política do Rio Grande do Sul e de suas figuras públicas, como mostra sua página principal:

Figura 7 - Interface Gráfica do Memorial do Legislativo

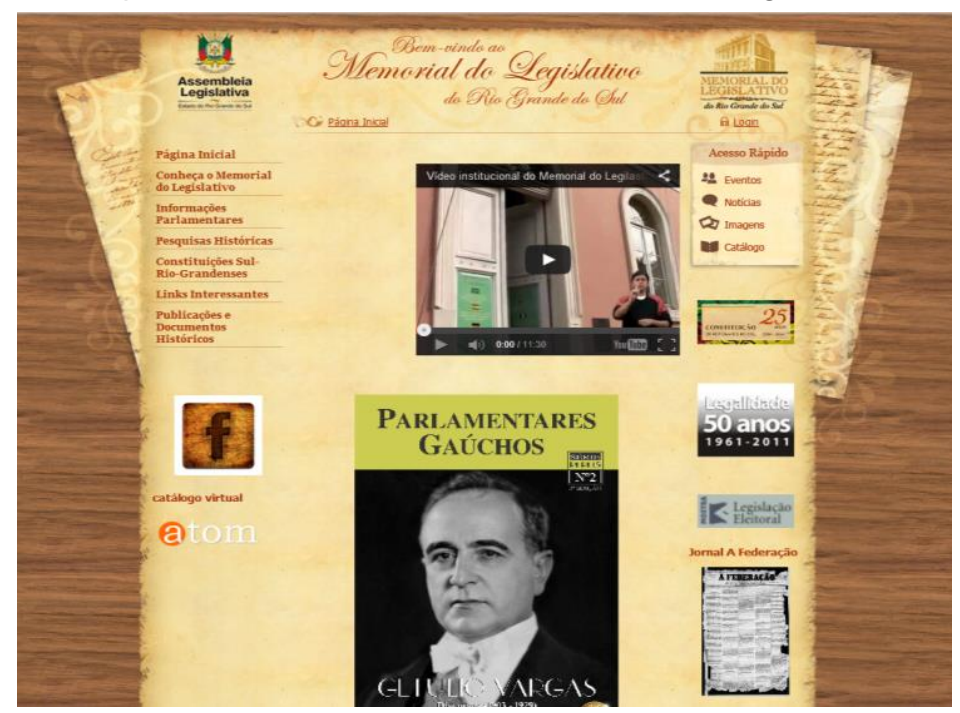

Fonte: Portal da Assembleia Legislativa do RS (RIO..., 2015)

A visibilidade destas três interfaces pode ser considerada de nível médio, pois não possuem destaque na página principal da ALRS, sendo acessadas apenas pela barra inferior da aba Institucional. A navegação, entretanto, é facilitada 
por canais de conteúdo interativo, que serão detalhados nos próximos itens do estudo.

\subsection{Interfaces gráficas das abas Legislativo, Comunicação e Deputados}

Considerando o direito à informação como um direito social, cabe à Assembléia Legislativa disponibilizar o produto do trabalho parlamentar: proposições, leis e outras normas legais. Nesse contexto, estão disponíveis, na aba Legislativo, diversas bases de dados, como mostra a Figura 8:

Figura 8 - Interface Gráfica da Aba Legislativo

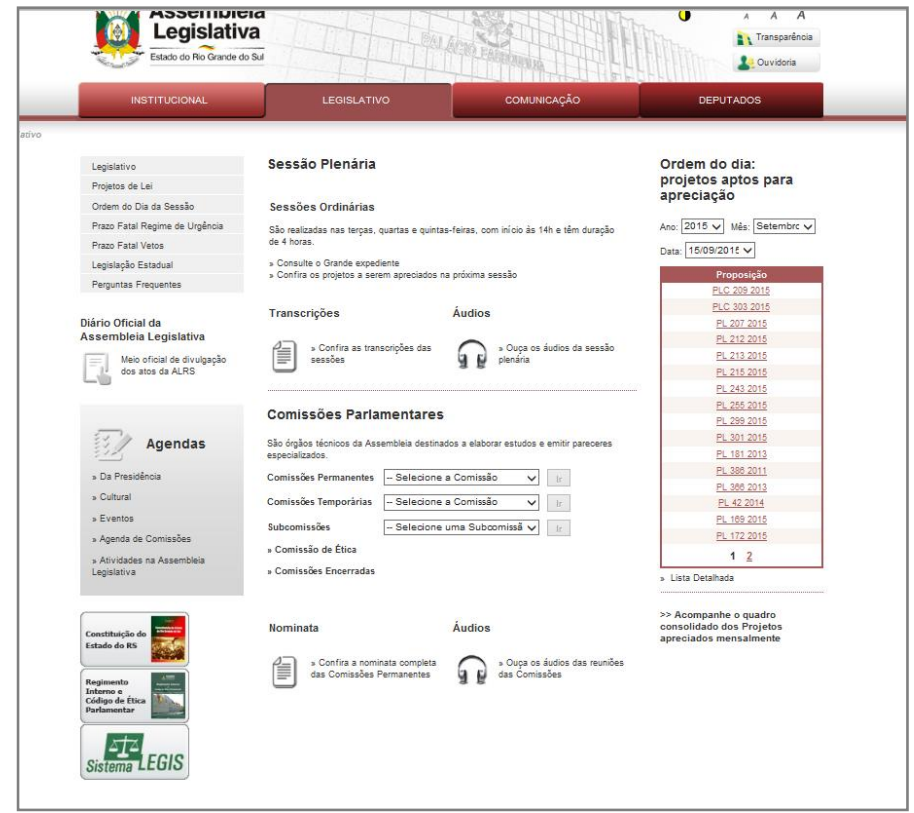

Fonte: Portal da Assembleia Legislativa do RS (RIO..., 2015)

O Sistema Legis é a base da legislação de hierarquia superior do Estado, com o texto de emendas constitucionais, leis complementares, leis ordinárias, decretos e resoluções da Assembléia Legislativa. A Legislação Compilada é um sistema que oferece as alterações das normas legais. Os projetos de lei estão disponíveis no Sistema de Proposições, e o Diário Oficial da Assembléia é o meio oficial de divulgação dos atos da instituição. Há também o acesso ao Regimento Interno e Código de Ética Parlamentar, à Constituição Federal e do Estado atualizadas e entre outras bases do processo legislativo, como o das Sessões Plenárias, das Comissões Parlamentares e da Ordem do Dia. Outro importante 
acesso são as Agendas - da Presidência, Cultural, Eventos e Comissões - que permitem a visualização das atividades estaduais programadas.

Na aba Comunicação, estão dispostos, como mostra a Figura 9, os canais de mídia da ALRS onde são divulgados os acontecimentos em destaque:

Figura 9 - Interface Gráfica da Aba Comunicação

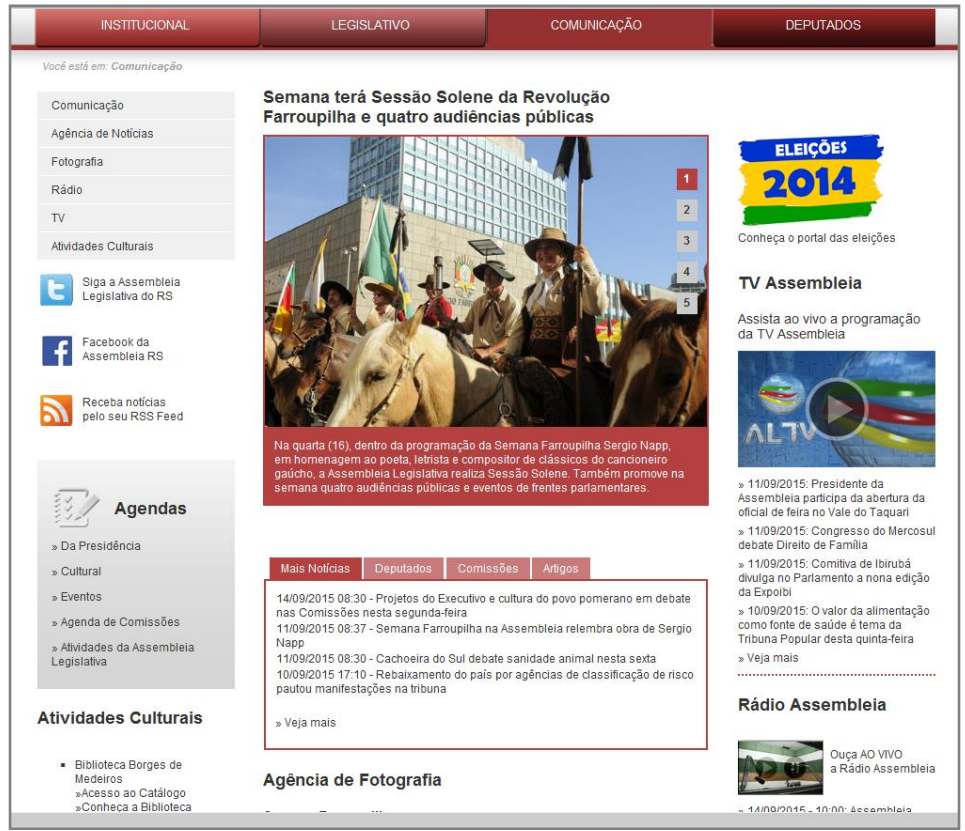

Fonte: Portal da Assembleia Legislativa do RS - (RIO..., 2015)

A área de Comunicação da ALRS deve divulgar as atividades parlamentares, fortalecer a imagem do Poder Legislativo, bem como promover as relações públicas e culturais com a sociedade. Para tanto, foram instituídos diversos canais de mídia, como a TVAL, a Rádio AL, a Agência de Notícias e a Agência de Fotos, que desenvolvem programas e matérias jornalísticas. O ambiente gráfico deste portal é altamente acessível e interativo.

Por último, na aba Deputados, estão dispostos a composição da Mesa e as bancadas partidárias, com links de acesso às páginas dos parlamentares da atual legislatura, como segue: 


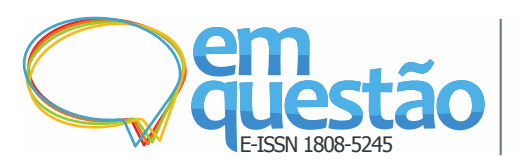

Figura 10 - Interface Gráfica da Aba Deputados

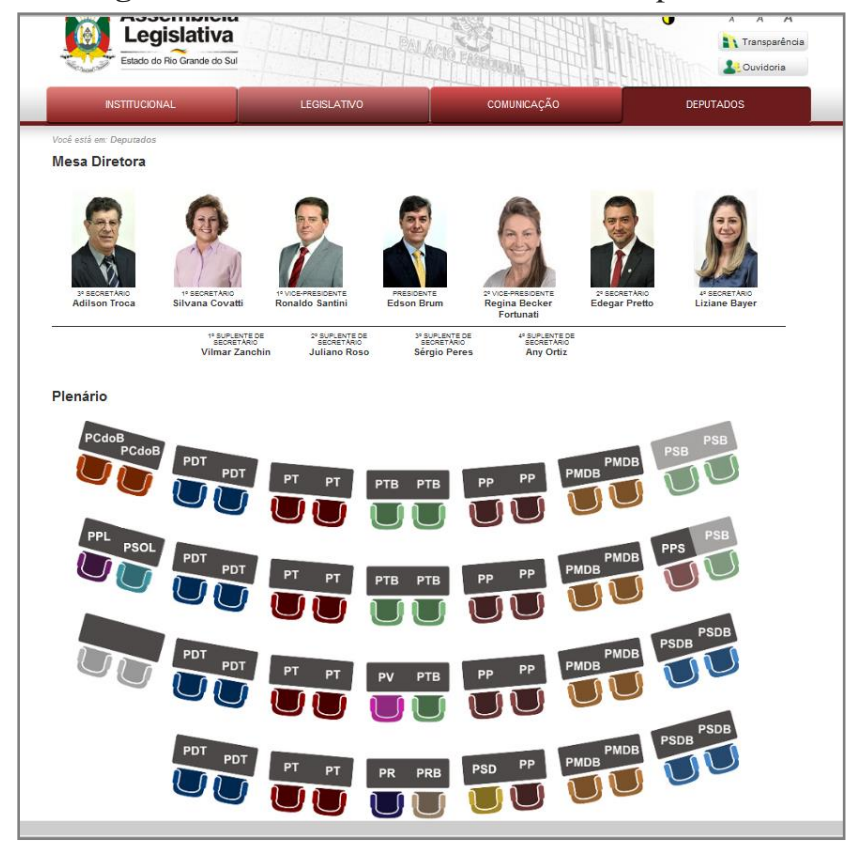

Fonte: Portal da Assembleia Legislativa do RS - (RIO..., 2015)

Pode-se observar, neste aba, que não há visibilidade imediata aos parlamentares. Apesar disso, o conteúdo é altamente interativo, como será analisado a seguir. Com um único clique sobre os ícones das bancadas, é possível acessar informações detalhadas de cada uma delas.

\subsection{Análise da interatividade do portal ALRS}

Para mensurar o nível de interatividade dos ambientes virtuais mapeados no portal da ALRS, serão utilizados os níveis identificados por Sims (1997), como segue: 
Quadro - Ambientes Gráficos segundo os Níveis de Interatividade de Sims (1997)

\begin{tabular}{|l|c|c|c|c|c|c|c|c|c|c|}
\hline \multirow{2}{*}{$\begin{array}{l}\text { Interfaces } \\
\text { Gráficas }\end{array}$} & Objeto & Linear & Suporte & $\begin{array}{c}\text { Atuali- } \\
\text { zação }\end{array}$ & $\begin{array}{c}\text { Constru } \\
\text { tiva }\end{array}$ & $\begin{array}{c}\text { Refle } \\
\text { xiva }\end{array}$ & $\begin{array}{c}\text { Simu } \\
\text { lação }\end{array}$ & $\begin{array}{c}\text { Hiper } \\
\text { linkada }\end{array}$ & $\begin{array}{c}\text { Contextual } \\
\text { não- } \\
\text { imersiva }\end{array}$ & $\begin{array}{c}\text { virtual } \\
\text { imersiva }\end{array}$ \\
\hline Transparência & $\mathrm{xxx}$ & $\mathrm{xxx}$ & $\mathrm{xxx}$ & $\mathrm{xxx}$ & --- & $\mathrm{xxx}$ & $\mathrm{xxx}$ & $\mathrm{xxx}$ & --- & --- \\
\hline $\begin{array}{l}\text { Ouvidoria } \\
\text { Legislativo }\end{array}$ & $\mathrm{xxx}$ & $\mathrm{xxx}$ & $\mathrm{xxx}$ & $\mathrm{xxx}$ & $\mathrm{xxx}$ & $\mathrm{xxx}$ & $\mathrm{xxx}$ & $\mathrm{xxx}$ & --- & --- \\
\hline $\begin{array}{l}\text { Biblioteca } \\
\text { Virtual }\end{array}$ & $\mathrm{xxx}$ & $\mathrm{xxx}$ & $\mathrm{xxx}$ & $\mathrm{xxx}$ & $\mathrm{xxx}$ & $\mathrm{xxx}$ & $\mathrm{xxx}$ & $\mathrm{xxx}$ & -- & -- \\
\hline $\begin{array}{l}\text { Memorial do } \\
\text { Legislativo }\end{array}$ & $\mathrm{xxx}$ & $\mathrm{xxx}$ & $\mathrm{xxx}$ & $\mathrm{xxx}$ & $\mathrm{xxx}$ & $\mathrm{xxx}$ & $\mathrm{xxx}$ & $\mathrm{xxx}$ & --- & -- \\
\hline $\begin{array}{l}\text { Aba Legislati- } \\
\text { vo }\end{array}$ & $\mathrm{xxx}$ & $\mathrm{xxx}$ & $\mathrm{xxx}$ & $\mathrm{xxx}$ & --- & --- & $\mathrm{xxx}$ & $\mathrm{xxx}$ & -- \\
\hline $\begin{array}{l}\text { Aba Comuni- } \\
\text { cação }\end{array}$ & $\mathrm{xxx}$ & $\mathrm{xxx}$ & $\mathrm{xxx}$ & $\mathrm{xxx}$ & --- & --- & $\mathrm{xxx}$ & $\mathrm{xxx}$ & -- & -- \\
\hline Aba Deputados & $\mathrm{xxx}$ & $\mathrm{xxx}$ & $\mathrm{xxx}$ & $\mathrm{xxx}$ & --- & --- & $\mathrm{xxx}$ & $\mathrm{xxx}$ & -- \\
\hline
\end{tabular}

Fonte: Dados da pesquisa

Tendo em vista que o grau de interatividade de uma interface gráfica depende do número de níveis presentes simultaneamente no ambiente, pode-se afirmar que os portais da Biblioteca Virtual e do Memorial do Legislativo são os mais interativos.

Entretanto, uma análise ampla permite inferir que, no geral, as interfaces gráficas contém alto nível de interatividade, embora os graus mais complexos contextual não-imersivo e virtual imersivo - não apareçam nos ambientes gráficos da ALRS. Porém, sabe-se que este tipo de interação é mais comum em portais de ensino/aprendizagem e de conhecimento técnico, como, por exemplo, no uso de inteligência artificial.

Todas as interfaces proporcionam navegação bastante flexível, visto que disponibilizam diversos links, permitem manipular objetos (ler arquivos na íntegra, imprimir, salvar em variados formatos, compartilhar, etc.), possuem resposta audiovisual, oferecem instruções para o usuário realizar buscas e também informações de suporte.

Os portais da Biblioteca e do Memorial permitem, ainda, a manipulação de registrar repostas inseridas pelos usuários e visualizar respostas anteriores, além de possibilitar, também, em todas as interfaces, que se opere a sequência de conteúdos.

As interfaces possuem canais de comunicação com o usuário - por email e redes sociais - além de formulários de contato. Pode-se inserir comentários, 
pesquisar (pesquisa básica e avançada, com operadores booleanos) e salvar conteúdo multimídia.

\section{Considerações finais}

Apesar do expressivo número de serviços oferecidos pela Assembleia Legislativa em seu portal, é preciso refletir sobre a forma de acesso a eles. O cidadão de hoje tem expectativas crescentes acerca da democratização do acesso à informatização. Consequentemente, a instituição precisa ser seletiva, crítica, criativa e ágil na oferta de serviços e produtos de informação, o que implica na adoção de instrumentos adequados e práticas modernas de gestão.

Se, por um lado, algumas necessidades dos usuários têm sido satisfeitas, por outro, depreende-se que o atendimento a essas demandas pode produzir um efeito multiplicador, gerando novos usuários e atingindo, indiretamente, outras camadas da população.

Considerando-se que o portal da ALRS provê visibilidade na informação e oferece uma gama de serviços, é possível inferir que pode atuar como facilitador do acesso à informação para os diversos segmentos sociais. Evidencia-se também, a partir desse conjunto de esforços e atividades, a importância da informação enquanto instrumento de disseminação do conhecimento e de execução da política institucional de estreitamento de relações com a sociedade.

Acredita-se, sobretudo, que, por meio de iniciativas de acesso público à informação, a Assembleia do Rio Grande do Sul esteja se aproximando cada vez mais da concretização de ideais de democratização da informação, levando a uma maior transparência de suas atividades e, principalmente, contribuindo para a construção da uma cidadania participativa. 


\section{Referências}

ACQUOLINI, Nicole Tirello. Revistas científicas eletrônicas: uma análise das interfaces quanto a suas possibilidades interativas. 2013. Trabalho de Conclusão de Curso (Graduação em Biblioteconomia)-Faculdade de Biblioteconomia e Comunicação,Universidade Federal do Rio Grande do Sul, Porto Alegre, 2013. Disponível em: <http://hdl.handle.net/10183/88822〉. Acesso em: 13 set. 2015.

BRASIL. Constituição da República Federativa do Brasil. Brasília (D.F.): Ed. do Senado Federal, 2015. Disponível em: <http://www.al.rs.gov.br>. Acesso em: 9 set. 2015.

BRASIL. Lei Federal 12.527, de 18 de novembro de 2011. Diário Oficial [da] União, Brasília, DF, 18 nov. 2011. Disponível em:

<http://www.planalto.gov.br/ccivil_03/_ato2011-2014/2011/lei/112527.htm>. Acesso em: 13 set. 2015.

BRASIL. Ministério do Planejamento, Orçamento e Gestão. O cidadão como parceiro: manual da OCDE sobre informação, consulta e participação na formulação de políticas públicas. Brasília, DF, 2002. Disponível em:

<http://www.oecdbookshop.org/get-it.php?REF=5LMQCR2K4JTF\&TYPE =browse $>$. Acesso em: 2 set. 2015.

CHOMSKY, Noam. Novos horizontes no estudo da linguagem e da mente. São Paulo: Ed. da UNESP, 2005.

FILATRO, A. Design instrucional na prática. São Paulo: Pearson, 2008.

GENTILLI, Victor. Cidadania e direitos: o direito à informação. In: GENTILLI, Victor. Democracia de massas: jornalismo e cidadania: estudo sobre as sociedades contemporâneas. Porto Alegre: EDIPUCRS, 2005. p. 125-139. 
LÈVY, Pierre. As tecnologias da inteligência. São Paulo: Editora 34, 1993.

LOPES, Cristiano Aguiar. Acesso à informação Pública. Brasília: Câmara dos Deputados, 2006. Disponível em: 〈http://www.camara.gov.br/biblioteca〉. Acesso em: 15 jan. 2008.

MARQUES JÚNIOR, Alaôr Messias; PIMENTA, Ana Lúcia Neves; FARIA, Rinaldo de Moura. A informação jurídica como instrumento para o exercício da cidadania. In: CONGRESSO BRASILEIRO DE BIBLIOTECONOMIA E DOCUMENTAÇÃO, 19., 2000. Proceedings... Porto Alegre: EDIPUCRS, 2000.

PESAVENTO, Sandra Jatahy. A trajetória do Parlamento gaúcho. 2. ed. Porto Alegre: Assembleia Legislativa do Rio Grande do Sul, 1996.

RIO GRANDE DO SUL. Portal da Assembleia Legislativa. 2015. Disponível em: <http://www.al.rs.gov.br> Acesso em: set. 2015.

SERPA, Angelo. Visibilidade. In: SERPA, Angelo. O espaço público na cidade contemporânea. São Paulo: Contexto, 2007. p. 69-106.

SILVA, Leticia Vieira da. Revistas científicas eletrônicas: aplicação e análise da arquitetura de informação nas interfaces das revistas PLOS Biology e Archives of Public Health. 2015. Trabalho de Conclusão de Curso (Graduação em Biblioteconomia)-Faculdade de Biblioteconomia e Comunicação,Universidade Federal do Rio Grande do Sul, Porto Alegre, 2015. Disponível em:

<http://hdl.handle.net/10183/122427>. Acesso em: 13 set. 2015.

SIMS, R. Interactivity: a forgotten art? Computer in Human Behavior, v. $13 \mathrm{n}$. 2 p. 57-80. May 1997. Disponível em:

<http://www2.gsu.edu/ wwwitr/docs/interact/> Acesso em: 13 set. 2015. 
TAPIA, Jorge Ruben Biton. Cidadania e Governo Eletrônico: algumas reflexões. In: MELO, José Marques de. (Org.). Sociedade do conhecimento: aportes latino-americanos. São Bernardo do Campo: UMESP, 2005. p. 177-191.

VIEIRA, Lizst. Os argonautas da cidadania: a sociedade civil e a globalização. Rio de Janeiro: Record, 2001.

\title{
Legislative information, access and citizenship
}

\begin{abstract}
This study highlights the main actions developed by Assembleia Legislativa do Rio Grande do Sul for the provision, through its web interface, of information rights and public access, through its Internet interface $(<\mathrm{http}$ : //www.al.rs.gov.br>). The specific objectives analyze the ALRS web interface and map graphical interfaces to verify the visibility of information and interactivity possibilities. The study identifies an average visibility and a high level of interactivity in the most graphic interfaces. Concludes, thus, that the web interface of the State Legislative is a definite public environment accessibility, which provides visibility and offers a range of multiple services, acting therefore as a easiness access to information.
\end{abstract}

Keywords: Access to information. Information rights. Visibility. Interactivity. Legislative information.

Recebido em 14/09/2015

Aceito em 20/11/2015 